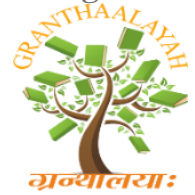

INTERNATIONAL JOURNAL OF RESEARCH GRANTHAALAYAH A knowledge Repository

Arts

\title{
DIGITAL TECHNIQUES OF PAINTING
}

\author{
Abhilasha Jaiswal *1 \\ ${ }^{* 1}$ Researcher, Shaskiya Maharani Laxmi Bai, Kila Maidan, Indore (M.P.)
}

\begin{abstract}
As technology is evolving gradually from the ages, the human way of living and different types of arts have also influenced. In these days the old energy consuming process has got extent and a creative fusion of the two worlds of art and technology is prevailing. Inspiringly, the background medium of this force which is fast developing into an indispensable asset is the digital age of computer. It's effect on the human life can be said to have secured unusual style in past 20th century, where the computer as a machine which uses codes and binary digits computerized to keep and achieve facts provided, were used in various ways to process easier the functions of particular absolutely necessary machines in human attempts to achieve a goal, until then it was done manually or by some other means.
\end{abstract}

Keywords: Techniques; Digital; Painting.

Cite This Article: Abhilasha Jaiswal. (2019). "DIGITAL TECHNIQUES OF PAINTING." International Journal of Research - Granthaalayah, 7(11SE), 150-153. https://doi.org/10.29121/granthaalayah.v7.i11.2019.3727.

\section{Introduction}

Digital art is evolutionary by time or nature. Fast development in technology and software applications also affected creative field of painting. Many other fields have also adapted digital technologies. Traditional art work techniques have changed, the ideas behind the process of creation is still the same but only the way of presentation or implementation has changed from canvas to digital file.

\section{Theoretical Framework}

Digital art in itself is divided into two parts:

1. Computer generated art

2. Computer aided art.

\section{Computer Generated Art}

Computer Generated art means, developing artworks using by self-control process with no direct human being control. The role of human being is to control the process; in this a person creates a 
computer program to initiate the process and to form the selection of generated artworks. Originally computers generated artworks are not affected by any type of artist's emotions. Computer generated art's examples are algorithmic art, random art, software art, artificial art, mathematical art, cellular automation art and fractal art.

\section{Computer Aided Art}

Computer aided art means that the computers great power is only supervised and operated by artist or users; output is achieved through the help of software programs and it is totally a creation of an artist. An artist uses digital technology as the product, as procedure or as the topic.

\section{Research Design}

The main research method used is quantitative analysis or describing in essence the process towards, a common survey followed by usage of various digital painting application software that was accessible like as, Corel draw, Corel photo paint, Adobe Photoshop, Adobe illustrator etc.

Some works were compared by the experts, and information collected for varied process towards using the software in painting and illustrations. This was done to get the conclusion that which application is appropriate and accurate result giving for the studio work. By this research I come to know that many young artists have happily adapted digital tools due to its easy-going options, economic expenditure and endless possibilities. It has great potential for developing new art forms. Gradually each and everything has become digital so how long art field will be untouched from it. New special effects and text tools are attracting young people to adapt digital working and it also makes their working easier and effective.

\section{Digital Techniques}

Now a Days advanced in digital painting system also many unique effects, brush strokes, blending tools gives digital painting experience a new level of pleasure. Digital artist generally uses stylus and digital pad called tablet for working. Digital painting is different from computer generated art, it is something drawing and painting on screen rather than physically on canvas and paints. For doing digital painting we require some software applications along with computer system. Some software like Adobe, Corel is needed for developing and giving shape to your idea on the screen. But main important thing is that its soul has to be given only by the artist rest of the things required to finish your work is provided by the applications. Painter John W Holloway when commenting on existing paint system said [ref: Baxter 2004]

"Within the art world, traditional painters have rejected the computer primarily for its inability to produce images that are not purely graphic in nature. There is no "organic-ness within digital images, for obvious reasons. These images tend to be too clean, too sterile, too flat and too temporal. The need for an artist to invoke a feeling of soul is problematic, and hardly fluid with the dominant digital technologies available."

In digital paintings artist can arrange their work layer by layer so it can be easily edited. Artist can use options like redo or undo to retouch his work. Applications provide millions of colours to choose without any cost and mess. Artist can use different 2D and 3D software's for developing 
the artwork. Work can be left on any point of stage and also redo on anytime without fear of destroying the outlook. A graphics tablet permits the artist to have very accurate hand movement to reproducing a real pen and drawing surface. The most important ability of the digital technology work is that it can be immediately showcased at a universal level online.

\section{Result}

The combination of artistic skills and technology was to elevate the quality of artwork and give new heights of perfection to the work. Digital painting is a computer-built work which is originally virtual, in its essence. It is developed in like vogue to non-digital painting by means of software applications. It is a new meadow of creative study or getting something new that conduct not only and authentic official erection but also a bright conceptual proceed towards to the visual form of arts, Because of the unique pliability of the digital age. This work can be immediately showed at a final output or as finished product level.

Somehow changes or editing in any stage or point of time is more possible in digital artwork as compared to the traditional art work. In this age of innovation, the artist's freedom would be complete and universal, in that sense the digital technology gives a lot of graphical interfaces, and ready to use effects which save artist's time and efforts. Digital technology of painting has given new opportunities and platform to artist with endless possibilities.

\section{Conclusion}

As time and technology is growing every field gets affected by it. So, artists and creative field cannot ignore it. Technology helps artists to move according to the time, to make work more effective and to show their talent universally. Through this universal approach artists get more audience by using online websites. Within a few second artist can show their talent to the entire world at a low expense.

However, in spite of this development of digital technology which gives wings to artist's creation, helping them to earn more, this revolution brings some demerits too, like anyone can create or replicate your work. Authenticity of an artwork is always remaining a concern. Like every coin has two sides this digital revolution also has enabled us to conserve old paintings of great masters. Many famous museums are using digital technology of painting and photography for restoration of their glorious ancient artworks. It totally depends on artists, how they use technology or software applications in their work. These soft-wares have endless possibilities, colours, effects and brush patterns to show your creativity.

\section{References}

[1] Adam, L. (1999). Art Across Time: Prehistory to the Fourteenth Century (Vol. New York, NY: Mc-Graw-Hill.)

[2] Chipp, H. B. (1998). Theories of Modern Art: A Source Book by Artists. New York, NY, U. S. A: University of California Press, 1968. Reprint New York University Press.

[3] Delahunt, M. (2004). Definition of Words and Terms in the Art Industry. Retrieved March 17, 2005, from Artlex Online Dictionary: http://www.artlex.com 
[4] Donald D. (1980). Micro Computing (Custom Version). Boston, Massachusetts: McGraw-Hill Companies Inc.

[5] Golding, J. (1994). Version of the Modern. California, CA, U. S. A: University of California Press.

[6] Hughes, R. (1991). The Shock of the New: The Life and Death of Modern Art (2nd ed.). Mc-Graw Hill.

[7] Marzuri, A. A. (2002). Cultural Amnesia, Cultural Nostalgia and False Memory:

[8] Africa Identity Crisis Revisited in African Philosophy (Vol. 13). United

[9] Kingdom: Carafax Publishing, Taylor and Francis Ltd.

[10] Nakian, R. (1985). The Studio Potter. Manchester, United Kingdom: Lew A. Cummings Co. Inc.

[11] Oguibe, O. (2002). Appropriation as Nationalism in Modern African Art. (Taylor, \& Francis, Eds.) Third Text.

[12] O'Leary, T. (1995). Computer Essentials (Brief Version). Madison Wisconsin: McGraw-Hill Companies Inc.

[13] Resnick, M. (1998). Technologies for Lifelong Kingdergarten. Educational Research and Development, IV (46).

[14] Rinder, L. (2002). Art in the Digital Age. New York, NY, U. S. A: Madison Press.

[15] Rubin, W. (1984). Primitivism in 20th Century Art. New York, NY, U. S. A: Museum of Modern Art (MOMA).

[16] Roger M. (2004). Digital Art Museum. Retrieved March 22, 2005, from The official website of the Digital Art Museum: http://www.dam.org/history

\footnotetext{
*Corresponding author.

E-mail address: artist.abhi@ gmail.com
} 